\title{
The Effect of Dignity Therapy on Hope in Patients with Major Depression Disorder
}

\author{
Saeed Vaghee ${ }^{1} \&$ Abbas Heydari ${ }^{1}$ \\ ${ }^{1}$ Evidence-Based Care Research Center, School of Nursing and Midwifery, Mashhad University of Medical \\ Sciences, Mashhad, Iran \\ Correspondence: Abbas Heydari, School of Nursing and Midwifery, Mashhad University of Medical Sciences, \\ 9137913199, Mashhad, Iran. Tel: 98-51-3859-1511. E-mail: HeidaryA@mums.ac.ir
}

$\begin{array}{lr}\text { Received: January 23, } 2016 & \text { Accepted: February 29, } 2016 \quad \text { Online Published: April 29, } 2016 \\ \text { doi:10.5539/gjhs.v8n12p118 } & \text { URL: http://dx.doi.org/10.5539/gjhs.v8n12p118 }\end{array}$

\begin{abstract}
Introduction: Despite the importance of the hope level increment in the patients with major depression disorder, fewer interventions have been applied to improve the hope level in the psychiatric patients, especially the depressed individuals.

Objective: To identify the dignity therapy effect on the hope level in the patients with major depression disorder.

Method: In this random controlled clinical trial, 58 patients with major depression disorder, who were hospitalized in Ibn-e-Sina psychiatric hospital of Mashhad, were separated into two intervention (28 individuals) and control (30 individuals) groups. The intervention group has taken the dignity therapy (based on the standard protocol in three 30-45 minutes sessions) and the control group have been undertaken the normal caregiving without intervention. The research tool was the Herth hope index, which was filled exactly before and after intervention. The data analysis has been done by SPSS 11.5 and exact Fischer tests, Chi square, independent t-test and paired t-test.
\end{abstract}

Results: 65.5 percent of the patients were female and 34.5 percent were male. Before the intervention, there was no significant statistical difference between the dignity therapy group (19.9 \pm 2.8$)$ and the control group (20.5 \pm 1.6$)$ in the average total hope score $(\mathrm{p}=0.39)$. However, the variations of the average total hope score before and after intervention between the dignity therapy group (4.7 \pm 2.9$)$ and the control group $(0.1 \pm 1.9)$ was significant $(\mathrm{p}<0.001)$.

Conclusions: According to the dignity therapy effect on the hope level increment in patients with major depression disorder, this unique and short clinical trial can be employed to increase the hope level in the patients with depression disorder.

Keywords: dignity therapy, hope, major depression disorder, clinical trial

\section{Introduction}

Major depression disorder is one of the most common and expensive mental disorders (Kessler et al., 2010), which reduces the life quality, workplace performance and causes perturbations in the family and social roles (Cuijpers, Beekman, \& Reynolds, 2012), while this disorder is the fourth main cause of the diseases in the whole world and it has a huge social and economic load (Ustun, Ayuso-Mateos, Chatterji, Mathers, \& Murray, 2004). The prevalence rate in the life time is 15 to 25 percent, which is two times more frequent in females than males (B. J. Sadock, V. A. Sadock, \& Ruiz, 2014). While, Sadeghi et al. have estimated the current depression prevalence rate is 4.1 percent, which shows the high prevalence rate of this disorder (Sadeghirad et al., 2010).

From the Aaron Beck's point of view, the negative self-examination, pessimism, hopelessness and other negative view points (which are the result of the cognitive misunderstanding of the life experiences) cause the depression feeling in the patients with major depression disorder, while these patients always see the negative side and assume that they fail in whatever they do (Sadock et al., 2014).

In recent years, positive thinking and having a hopeful view to the life has been a major point of interest between the psychologists and humanities scientists in psychological diseases, especially in hopelessness and depression therapies (Parham, Fatehizade, \& Mohagheghan, 2013). According to them, the hopeful and optimist individuals 
deal better with the psychological pressure by implementing the more effective confronting methods such as second examination and solutions; also, they actively avoid the life stressful events and construct better social networks in their environment (Pashasharifi \& NajafiZand, 2011; Seligman \& Csikszentmihalyi, 2000) also showed that the unique abilities of the human such as courage, hope and optimism, which are neglected in the traditional psychology can be a barrier in front of the psychological disorders (Arnau, Rosen, Finch, Rhudy, \& Fortunato, 2007). In addition, (Snyder, 2000) has investigated the hope scientifically and conceptualized it as a structure, which consists of the bypass designing ability to the desired goals despite the existing barriers and also an agency (motivation to use these bypasses). According to this conceptualization, the hope is powerful when it is consists of valuable goals or there is a possibility to achieve these goals in a finite time (Arnau et al., 2007). Also, Dufault et al introduced hope as a multidimensional dynamic life force that is characterized by a confident yet uncertain expectation of achieving good, which is realistically possible and personally significant (Dufault, 1985).

Depression and hopelessness also appear because of obstruction and not achieving the goals, which were crucial for the individual (Elliott, Witty, Merrick, \& Toffman, 1991). Because the patients who suffer from the depression relate the negative life events to the internal causes which are fixed and are not controllable; hence, they lose the required motivation in their life and predict failure in their work. Also, they feel absurdity in their lives because of their hopeless feeling of the future and they prefer death (Kushan \& Vaghee, 2013; Kushan \& Vaghee, 2003).

On the other hand, the perception of the hope is practically essential for the nurses and it seems that it is an important factor in the psychological proceedings effectiveness and compatibility with chronical diseases in the patients with major depression disorder (Sanatani et al., 2008), while nurses are able to affect the hope level in these patients by their presence, talking and giving information, politeness and honesty (Son et al., 2009).

In addition, the research of Chochinove et al. resulted in a new and unique psychological therapy method, named dignity therapy (Chochinov, 2010). This method is employed for all individuals who have experienced high levels of stress in a long period (Chochinov, 2010) and has a narration approach, which consists of life revision and telling memories (Houmann et al., 2010). In fact, this method induces the feeling of being important in the patients by focusing on human relations enhancement and love phrases (Fitchett et al., 2015); hence, it can improve the hope level and being targeted in life by life story telling and narrating the most important thoughts, feelings and hopes (Chochinov, 2010), while in Vaghee et al.'s research in Iran, dignity therapy resulted in hope level increment in patients with chronic renal failure who were under hemodialysis (Vaghee et al., 2012). Moreover, dignity therapy has improved the hope level in cancer patients in Hall et al.'s research in United States of America (Hall et al., 2011).

All of the researches in the dignity therapy field are related to the chronic somatic disorders (Chochinov, 2010; Hall et al., 2011; Vaghee et al., 2012; Bentley, 2012; Miguel et al., 2014; Aoun et al., 2015); however, this method has been introduced as the antidote of depression (Fitchett et al., 2015) which can help the chronic mental patients to improve their accordance skills and self-worth beside keeping and improving the hope level and life meaning. Also, the Avery case report has shown the effect of dignity therapy on reducing the depression signs in patients with major depression disorder (Avery \& Baez, 2012, May) and Namdari et al.'s research in Iran demonstrated that education of hope increment can result in better recovery of the individuals with dysthymic disorder (Namdari, Molavi, Malekpoor, \& Kalantari, 2011).

Therefore, as the hope level increment and valuableness feeling in the patients with major depression disorder results in expediting their recovery and reducing the hospitalization period in the hospital and hence it gives them independency and more self-politeness (Kushan \& Vaghee, 2015). On the other hand, according to the high level of depression prevalence and decrement of the hope level, fewer researches have been done on the mental disorders such as depression in Iran because of the wrong diagnosis. Hence, the main contribution of this paper is to study the effect of dignity therapy on hope level of the patients with major depression disorder.

\section{Method}

This random control clinical trial has been performed in Ibn-e-Sina hospital of Mashhad on the patients with major depression disorder in 2015-2016. The diagnosis of the disorder has been approved by the patients' psychologist based on DSM-V classification and has been recorded in the patients' profile. The sample volume has estimated to be 26 individuals in each group, while by taking in to account the 15 percent of sample decrement, 30 individuals in each group (total 60 individuals) were studied. According to the intervention conditions, sampling has been done individually from the patients who were in the euthymic state and confirmed by the psychiatrist. This process has been continued for about four months to complete the final volume. In the 
final part of this study, two patients from the dignity therapy group has been omitted from the study because one could not attend the after test examination and one did not tend to continue the dignity therapy sessions. Therefore, the final volume sample consists of 58 individuals (30 individuals in the control group and 28 individuals in dignity therapy group).

The including criterions of this study consist of definite diagnosis of major depression disorder, the age between 18 and 60 years, the ability to at least read or write, the existence of no simultaneous mental and somatic disorder, no intention to go on a trip immigrate to another city for two months after leaving hospital and having the major depression disorder for more than three years. The excluding criterion also consist of: not having required cooperation of the patient for the therapy protocol, not having the required cooperation of the patient's family or friends to intend in the research environment and receiving generating document, any sudden upcoming events in the patient's life, or being diagnosed by another mental disorder by the psychiatrist in the research period.

The data collecting tool in this research was the demographic and disease information form, Herth hope index, and human dignity questionnaire. The demographic information form consisted of nine questions, which has been conducted based on the research goals. The Herth hope index, is the normalized form of the standard questionnaire of Herth hope, which consists of 12 questions and 3 under-criterions of cognitive-temporal (questions 1,2,6,11), emotional-behavioral (questions 4,7,10,12) and relational-background (questions 3,5,8,9), while each of the under-criterions is investigated by 4 questions. The questions of the Herth hope index based on Likert scale, from 1 to 3 ( $1=\mathrm{I}$ disagree, $2=\mathrm{I}$ am not sure, $3=\mathrm{I}$ agree), questions 3 and 6 are scored reversely. The total hope score is 12 to 36 , while the higher score shows the higher level of hope. On the other hand, the score between 12 and 24 is the lowest level of hope, the score between 25 and 30 is the intermediate level and the score of 31 to 36 shows the high level of hope. The validation of the translation and this tool's content has been confirmed by Shafiei (Shafie, 2010) and Abdi et al. in Iran (Abdi, Hossein Taghdisi, \& Naghdi, 2007). The stability of this questionnaire has been also confirmed in the Poorghaznein research in the patients under kidney transplantation by test-retest with Pearson correlation coefficient of 0.78 (Poorghaznein \& Ghaffari, 2004). In this research, the stability of the questionnaire also has been confirmed again by the test-retest method with the correlation of 0.82 .

Sampling was first done by the non-randomized method (simple sampling) from the patients with depression disorder, hospitalized in the Ibn-e-Sina hospital of Mashhad; in which the records of the hospitalized patients who have been definitely diagnosed to have major depression disorder by psychiatrist in the final week of hospitalization and there has been about one month from their hospitalization has been entered in the control or intervention group in case of mental stabilization confirmation by the psychiatrist and tendency to enter the research after getting the testimonial and also the Herth hope index was completed for both of the groups.

In the intervention group, the dignity therapy has been performed based on its standard protocol; in which first, the conditions of sessions, type and style of questions and answering has been reviewed in a 25-30 session. After that, in two 30-45 minute sessions in two sequential days, the protocol's questions (including 12 questions) were proposed one by one and the individual had the opportunity to remember and tell the life aspects in which he or she has been proud, the problems that have been and are meaningful to him or her, a life's part or his or her demands. The answers of the patient has been recorded, written and edited and returned to the patient as a generating document to be completed after correction. The generating document has been given to a family member or a friend of the patient by the patient's selection after the final acceptance to be shared with whom the patient tends to. Information collection in the intervention and control group has been done separately for each individual before their random grouping (pre-test) and after two months (post-test) based on the scheduled table (according to the sampling time). According to the research ethics, in the final level of the information collection, two educational sessions have been held in the major depression disorder field, its signs and therapy for both of the groups.

The whole research ethics points, approved in the medical university research assistance organization (No. 940193/222), which were related to the present study have been used. These points consisted of receiving the written approval form from the university's ethics committee, receiving the written approval form from the research participants, coding the questionnaire in order to protect the participants' secrets and confide them to exit the research in any time they were not willing to continue.

The research data has been processed by SPSS 11.5 software. Exact Fischer tests, Chi square, independent t-test have been implemented to investigate the homogeneity of the qualitative and quantitative variables. Independent $\mathrm{t}$-test has been also employed for comparison between the groups and paired t-test has been used for the in-group comparison. The confidential level and the meaning levels have been assumed to be 95 percent and 0.05 
respectively.

\section{Results}

According to Table 1, the intervention and control group were homogeneous and there has been no significant statistical difference between these two groups from the demographic information point of view $(p<0.05)$. In the demographic information field, in the intervention group, more numerous individuals were female (60.7 percent) with elementary education ( 42.18 percent), divorced (67.8 percent) and unemployed ( 89.3 percent) with average age level of $42.1 \pm 11.6$. In the control group also more numerous individuals were female (70 percent) with elementary education (46.7 percent), divorced ( 73.3 percent) and unemployed (90 percent) with average age level of $44.3 \pm 10.7$. The average duration of the depression disorder in all the research units was $4.7 \pm 5.6$ years, while the two groups were similar and there was no significant difference between them (Table 2).

Table 1. The population properties of the patients with major depression disorder for the intervention and control groups

\begin{tabular}{|c|c|c|c|}
\hline Group & Control group & Intervention group & \multirow{2}{*}{ Test result } \\
\hline Variable & Population (\%) & Population (\%) & \\
\hline \multicolumn{4}{|l|}{ Sex } \\
\hline Male & $9(30.0)$ & $11(39.3)$ & \multirow{2}{*}{$\mathrm{P}=0.46 *$} \\
\hline Female & $31(70.0)$ & $17(60.7)$ & \\
\hline \multicolumn{4}{|l|}{ Educational level } \\
\hline Elementary school & $14(46.7)$ & $12(42.8)$ & \\
\hline $8^{\text {th }}$ grade in high school & $6(20.0)$ & $6(21.4)$ & \multirow{3}{*}{$\mathrm{P}=0.82 *$} \\
\hline Diploma & $7(23.3)$ & $5(17.8)$ & \\
\hline Academic education & $3(10.0)$ & $5(17.8)$ & \\
\hline \multicolumn{4}{|l|}{ Marital status } \\
\hline divorced & $22(73.3)$ & $19(67.8)$ & \multirow{4}{*}{$\mathrm{P}=0.70^{*}$} \\
\hline Single & $4(13.4)$ & $5(17.8)$ & \\
\hline married & $3(10.0)$ & $4(13.4)$ & \\
\hline widowed & $1(3.3)$ & $0(0.0)$ & \\
\hline \multicolumn{4}{|l|}{ Working status } \\
\hline working & $3(10.0)$ & $3(10.7)$ & \multirow{2}{*}{$\mathrm{P}=0.63 * *$} \\
\hline Non-working & $27(90.0)$ & $25(89.3)$ & \\
\hline Age & $44.3 \pm 10.7$ & $42.1 \pm 11.6$ & $\mathrm{P}=0.47 * * *$ \\
\hline
\end{tabular}

* Chi-Square Test; ** Fisher Exact Test; *** Independent t-test.

Table 2. Average and standard deviation of the major depression disorder patient duration (year) in both of the dignity therapy groups

\begin{tabular}{llll}
\hline Groups & Population & Average \pm standard deviation & Standard t-test results \\
\hline Intervention group & 28 & $9.6 \pm 6.2$ & $\mathrm{t}=0.29$ \\
Control group & 30 & $10.0 \pm 6.0$ & $\mathrm{df}=56$ \\
Total & 58 & $4.7 \pm 5.6$ & $\mathrm{p}=0.77$ \\
\hline
\end{tabular}

Table 3. The group comparison of the hope level and its aspects in the patients with major depression disorder for the intervention and control groups

\begin{tabular}{lllll}
\hline \multirow{2}{*}{ Groups } & Before intervention & $\begin{array}{l}\text { Two months after } \\
\text { intervention }\end{array}$ & $\begin{array}{l}\text { Statistical Difference in } \\
\text { the evaluation level }\end{array}$ \\
\cline { 3 - 5 } & $\begin{array}{l}\text { Average } \pm \text { standard } \\
\text { deviation }\end{array}$ & $\begin{array}{l}\text { Average } \pm \text { standard } \\
\text { deviation }\end{array}$ & $\begin{array}{l}\text { Average } \pm \text { standard } \\
\text { deviation }\end{array}$ \\
\hline Cognitive-temporal & $\begin{array}{l}\text { Intervention } \\
\text { group }\end{array}$ & $6.5 \pm 1.4$ & $7.2 \pm 1.3$ & $0.6 \pm 1.4$ \\
& Control & $6.6 \pm 1.3$ & $6.7 \pm 1.1$ & $0.1 \pm 0.6$ \\
\hline
\end{tabular}




\begin{tabular}{|c|c|c|c|c|}
\hline & group & & & \\
\hline & & $\mathrm{P}=0.94^{*}, \mathrm{t}=0.08$ & $\mathrm{P}=0.11, \mathrm{t}=1.62$ & $\mathrm{P}=0.08, \mathrm{t}=1.82$ \\
\hline \multirow{3}{*}{ Emotional-behavioral } & $\begin{array}{l}\text { Intervention } \\
\text { group }\end{array}$ & $7.0 \pm 1.0$ & $8.3 \pm 1.5$ & $1.2 \pm 1.0$ \\
\hline & $\begin{array}{l}\text { Control } \\
\text { group }\end{array}$ & $6.9 \pm 0.8$ & $7.2 \pm 1.3$ & $0.3 \pm 1.3$ \\
\hline & & $\mathrm{P}=0.77^{*}, \mathrm{t}=0.29$ & $\mathrm{P}=0.003, \mathrm{t}=3.08$ & $\mathrm{P}=0.002, \mathrm{t}=3.23$ \\
\hline \multirow{3}{*}{ Relational-background } & $\begin{array}{l}\text { Intervention } \\
\text { group }\end{array}$ & $6.3 \pm 1.5$ & $9.1 \pm 1.3$ & $2.8 \pm 1.7$ \\
\hline & $\begin{array}{l}\text { Control } \\
\text { group }\end{array}$ & $6.9 \pm 1.0$ & $6.7 \pm 1.8$ & $-0.2 \pm 0.1$ \\
\hline & & $\mathrm{P}=0.09^{*}, \mathrm{t}=1.67$ & $P \leq 0.001, t=8.42$ & $P \Leftrightarrow 0.001, t=8.10$ \\
\hline \multirow{3}{*}{ Total hope } & $\begin{array}{l}\text { Intervention } \\
\text { group }\end{array}$ & $19.9 \pm 2.8$ & $24.7 \pm 2.2$ & $4.7 \pm 2.9$ \\
\hline & $\begin{array}{l}\text { Control } \\
\text { group }\end{array}$ & $20.5 \pm 1.6$ & $20.6 \pm 1.7$ & $0.1 \pm 1.9$ \\
\hline & & $\mathrm{P}=0.39^{*}, \mathrm{t}=0.88$ & $\mathrm{P}<0.001, \mathrm{t}=7.8$ & $\mathrm{P}<0.001, \mathrm{t}=7.21$ \\
\hline
\end{tabular}

* Independent t-test

Table 4. The in-group comparison of the hope level and its aspects in the patients with major depression disorder for the intervention and control groups

\begin{tabular}{|c|c|c|c|c|c|}
\hline \multirow[t]{2}{*}{ Groups } & & $\begin{array}{l}\text { Before } \\
\text { intervention }\end{array}$ & $\begin{array}{l}\text { Two months after } \\
\text { intervention }\end{array}$ & $\begin{array}{l}\text { Statistical } \\
\text { Difference in the } \\
\text { evaluation level }\end{array}$ & $\begin{array}{l}\text { P-value } \\
\text { (Paired } \\
\text { t-test) }\end{array}$ \\
\hline & & $\begin{array}{l}\text { Average } \pm \text { standard } \\
\text { deviation }\end{array}$ & $\begin{array}{l}\text { Average } \pm \text { standard } \\
\text { deviation }\end{array}$ & $\begin{array}{l}\text { Average } \pm \text { standard } \\
\text { deviation }\end{array}$ & \\
\hline \multirow{3}{*}{ Cognitive-temporal } & $\begin{array}{l}\text { Intervention } \\
\text { group }\end{array}$ & $6.5 \pm 1.4$ & $7.2 \pm 1.3$ & $0.6 \pm 1.4$ & $\begin{array}{l}\mathrm{P}=0.03 \\
\mathrm{t}=2.22\end{array}$ \\
\hline & $\begin{array}{l}\text { Control } \\
\text { group }\end{array}$ & $6.6 \pm 1.3$ & $6.7 \pm 1.1$ & $0.1 \pm 0.6$ & $\begin{array}{l}\mathrm{P}=0.57 \\
\mathrm{t}=0.57\end{array}$ \\
\hline & $\begin{array}{l}\text { Intervention } \\
\text { group }\end{array}$ & $7.0 \pm 1.0$ & $3.3 \pm 1.5$ & $1.2 \pm 1.0$ & $\begin{array}{l}\mathrm{P}<0.001, \\
\mathrm{t}=6.62\end{array}$ \\
\hline Emotional-behavioral & $\begin{array}{l}\text { Control } \\
\text { group }\end{array}$ & $6.9 \pm 0.8$ & $7.2 \pm 1.3$ & $0.3 \pm 1.3$ & $\begin{array}{l}\mathrm{P}=0.26 \\
\mathrm{t}=1.14\end{array}$ \\
\hline \multirow{2}{*}{ Relational-background } & $\begin{array}{l}\text { Intervention } \\
\text { group }\end{array}$ & $6.3 \pm 5.5$ & $9.1 \pm 1.3$ & $2.8 \pm 1.7$ & $\begin{array}{l}\mathrm{P}<0.001, \\
\mathrm{t}=8.56\end{array}$ \\
\hline & $\begin{array}{l}\text { Control } \\
\text { group }\end{array}$ & $6.9 \pm 1.0$ & $6.7 \pm 0.8$ & $0.2 \pm 0.1$ & $\begin{array}{l}\mathrm{P}=0.21 \\
\mathrm{t}=1.27\end{array}$ \\
\hline \multirow{2}{*}{ Total hope } & $\begin{array}{l}\text { Intervention } \\
\text { group }\end{array}$ & $19.9 \pm 2.8$ & $24.7 \pm 2.2$ & $4.7 \pm 2.9$ & $\begin{array}{l}\mathrm{P}<0.001, \\
\mathrm{t}=8.74\end{array}$ \\
\hline & $\begin{array}{l}\text { Control } \\
\text { group }\end{array}$ & $20.5 \pm 1.6$ & $20.6 \pm 1.7$ & $0.1 \pm 1.9$ & $\begin{array}{l}\mathrm{P}=0.77 \\
\mathrm{t}=0.29\end{array}$ \\
\hline
\end{tabular}

The independent t-test results in group comparison, shown in Table 4 demonstrated that there was no significant statistical difference in the average total hope score before and after intervention between the two groups $(\mathrm{P}=0.39)$; however, the average variations of the total hope score before and after two month of intervention between the intervention and control groups was significant $(\mathrm{P}<0.001)$.

In addition, according to Table 4, the paired t-test results of the in-group comparison revealed that there has been a significant difference in the total hope score in the intervention group $(\mathrm{P}<0.001)$; however, there has been no significant difference in the aforementioned score in the and control group $(\mathrm{P}=0.77)$.

On the other hand, in Table 4, according to the independent t-test results, there was no significant statistical difference between the average scores of the various aspects of the hope before and after the intervention in the intervention and control groups ( $p>0.05$ ); however, the independent $t$-test results show a significant statistical 
difference between the two groups for the average score variations of the emotional-behavioral and relationalbackground aspects before and after the intervention $(p<0.05)$; despite the fact that it did not show a significant statistical difference between these groups from the average score variations of the cognitive-temporal aspect before and after the intervention $(\mathrm{p}=0.08)$.

On the other hand, according to Table 4, the paired t-test in the in-group comparison demonstrated that there is a significant statistical difference between the average score of the cognitive-temporal, emotional- behavioral and relational-background before and two months after the intervention $(p<0.05)$; however, no significant statistical difference in the mentioned scores has been observed in the control group before and two months after the intervention $(\mathrm{p}>0.05)$.

\section{Discussion}

The contribution of this research was to reveal the effect of dignity therapy on hope level of the patients with major depression disorder, hospitalized in the Ibn-e-Sina psychiatric hospital of Mashhad. According to the results, the average total score of the hope level has been increased significantly after the dignity therapy in comparison to the control group. Hence, dignity therapy can improve the hope level of the patients with major depression disorder. This results has been verified by the Vaghee et al.'s research based on the dignity therapy effect on hope level improvement in the patients with chronic renal disease under hemodialysis (Vaghee et al., 2012; Hall et al., 2011b) and Montross-Thomas et al.'s research based on the dignity therapy effect on the hope level increment of the cancer patients (Montross-Thomas et al., 2015). In addition, Holmerová et al's research, based on Dignity and palliative care in dementia, confirm our study results. (Holmerová et al., 2007) Also, Vilhauer et al.'s research (2013) based on the effect of future directed therapy on disappointment and depression recovery on the patients with major depression disorder confirms the present study's results (Vilhauer et al., 2013).

The cognitive theory is one of the various theories which have been presented for the major depression disorder's reasons. According to these theories, individuals get depressed because they interpret their life events with pessimistic and disappointing views. Aaron Beck is one the most criticizing theorists in this field. He has presented the negative thoughts of the depressed individuals in three cognitive levels, which consists of the negative self-thoughts, negative thoughts about the present and future experiences; while the negative thoughts itself includes the belief of the depressed individual that he/she is not valuable and incompetent. In fact, disappointment and hopelessness show the negative view of the depressed individual of the future because the depressed individuals believe that their incompetence and defects prevents them from creating better conditions (Porafkari, 2005).

Another cognitive view of the depression focuses on various causal documents. According to this theory, the individuals who tend to relate the negative events to the internal, fixed, and non-variable causes tend to be more depressed rather than the individuals who are less pessimistic (Porafkari, 2005). The dignity therapy program forces the patients with major depression disorder to think about their positive points by providing the generating document, while the individual gets back to the period before the depression by remembering the memories with the pride and success emotions and he/she investigates about the goals, which caused success in the past. In addition, the patient finds the goals and life meaning unconsciously by decision making and thinking about the future goals and hope for living will be formed in the patient.

On the other hand, the effect of dignity therapy was different on the various aspects of hope. While the results of the present research showed that the dignity therapy schedule was effective on the emotional-behavioral and relational-background aspects but not on the cognitive-temporal aspect.

The cognitive-temporal aspect of the hope presents the positive thinking about life, without being afraid of the future and it shows the targeted today and tomorrow (Shafie, 2010). The dignity therapy was effective to some extent; however, it was not significant from the statistical point of view. According to Beck, the negative self-thoughts of the depressed individual have been created in the childhood and adolescence by experiences such as absence of the parents, social rejections, teachers or parents criticizes or a series of bad accidents and these will be activated at any time when new circumstances, similar to the ones that the beliefs have been taught come up and shows depression (Porafkari, 2005). Hence, dignity therapy is not able to change these beliefs and negative thoughts, which are related to the childhood.

However, dignity therapy was effective on the emotional-behavioral aspect of the hope, which implies targeted actions. Talking about the past successfulness gives the control emotion and life administration to the patient by remembering the happy and joyful days and the therapist also, as a hope source (by accompanying and improving the patience and paying attention to the patient and his/her family) accompanies the patient in 
remembering such memories (Shafie, 2010); hence, the targeted performance of the patient improves.

Also, in this research, dignity therapy was effective on the relational-background aspect of the hope, which shows the relation between the patient, others, and God as the greatest power (Shafie, 2010) because the lack of required communication skills and reaction to others is one of the prevalent problems of the patients with major depression disorder (Kushan \& Vaghee, 2015). The therapist improves the patient's communications with others and even the patient and God by expressing the emotions and the dreams of the patient for the others by means of the generating document in the dignity therapy schedule (Houmann et al., 2010).

The results of the dignity therapy effect on the cognitive-temporal aspect in the present research is different with the results of Vaghee et al's research based on the dignity therapy effect on hope level improvement in the patients with chronic renal disease under hemodialysis (Vaghee et al., 2012; Bentley et al., 2012; Hall et al., 2011) and Montross-Thomas et al's research based on the dignity therapy effect on the hope level increment of the cancer patients (Montross-Thomas et al., 2015). The difference of the society (the advanced chronic somatic disorders in comparison the chronic mental disorders) can be one of the reasons for the aforementioned difference in the results because hopelessness in the chronic somatic disorders is the result of the somatic and circumferential conditions of the patient and it is real according to the patient's pain. However, hopelessness is one of the main signs of the major depression disorder, which causes prostration and weakness feeling in these patients which are the result of the patient's negative interpretation of the reality (Sadeghirad et al., 2010).

\section{Conclusions}

The results of this study showed that the dignity therapy can improve the hope level in the patients with major depression disorder. Hence, this short-term and unique method can be implemented to improve the hope level in the patients with depression disorder. The investigation of the dignity therapy effect on the depression sign in the patients who are spending their first days of hospitalization is recommended in the future studies.

\section{Acknowledgements}

This research has been approved by the clinical trial code IRCT2015112625250N1 of the research project with code 940193 in July 6th 2015 by the research administration of Mashhad University of Medical Sciences. The authors sincerely acknowledge the financial help of the above mentioned university. They would also acknowledge the cooperation of the Nursing and Midwifery School of Mashhad and Ibn-e-Sina psychiatric Hospital of Mashhad staff.

\section{Competing Interests Statement}

The authors declare that there is no conflict of interests regarding the publication of this paper.

\section{References}

Abdi, N., HosseinTaghdisi, M., \& Naghdi, S. (2007). The Effects of Hope Promoting Interventions on Cancer Patients. A Case Study in Sanandaj, Iran, in 2007. Armaghan Danesh, 14(3), 13-22.

Aoun, S. M., Chochinov, H. M., \& Kristjanson, L. J. (2015). Dignity therapy for people with motor neuron disease and their family caregivers: A feasibility study. Journal of Palliative Medicine, 18(1), 31-37. http://dx.doi.org/10.1089/jpm.2014.0213

Arnau, R., Rosen, D., Finch, J., Rhudy, J., \& Fortunato, V. (2007). Longitudinal Effects of Hope on Depression and Anxiety: A Latent Variable Analysis. Journal of Personality, 75(1), 43-64. http://dx.doi.org/10.1111/ j.1467-6494.2006.00432.x

Avery, J. D., \& Baez, M. A. (2012, May). Dignity Therapy for Major Depressive Disorder: A Case Report. Journal of Palliative Medicine, 15(5), 509. http://dx.doi.org/10.1089/jpm.2011.0522

Bentley, B., Aoun, S. M., O'Connor, M., Breen, L. J., \& Chochinov, H. M. (2012). Is Dignity Therapy Feasible to Enhance The End of Life Experience for People with Motor Neurone Disease and Their Family Carers? BMC surgery, 11(18), 2-7. http://dx.doi.org/10.1186/1472-684x-11-18

Chochinov, H. M. (2010). Dignity therapy: Final Words for Final Days, A Handbook for Clinician.

Cuijpers, P., Beekman, A. T. F., \& Reynolds, C. F. (2012). Preventing Depression: A Global Priority. JAMA Psychiatry, 307(10), 1033-1034. http://dx.doi.org/10.1001/jama.2012.271

Dufault, K., \& Martocchio, B. C. (1985). Hope: Its spheres and dimensions. Nursing Clinic North America, 20(2), 379-391.

Elliott, T. R., Witty, T. E., Merrick, S., \& Toffman, J. (1991). Negotiatating reality after physical loss: Hope, 
depression and disability. Journal of Personality and Social Psychology, 61(4), 608-613. http://dx.doi.org/ $10.1037 / 0022-3514.61 .4 .608$

Fitchett, G., Emanuel, L., Handzo, G., Boyken, L., \& Wilkie, D. J. (2015). Care of the Human Spirit and the Role of Dignity Therapy: A Systematic Review of Dignity Therapy Research. BMC Palliative Care, 14, 2-12. http://dx.doi.org/10.1186/s12904-015-0007-1

Hall, S., Goddard, C., Opio, D., Speck, P. W., Martin, P., \& Higginson, I. J. (2011a). A novel approach to enhancing hope in patients with advanced cancer: A randomised phase II trial of dignity therapy. $B M J$ Supportive \& Palliative Care, 10(1136). http://dx.doi.org/10.1136/bmjspcare-2011-000054

Hall, S., Goddard, C., Opio, D., Speck, P. W., Martin, P., \& Higginson, I. J. (2011b). A Novel Approach to Enhancing Hope in Patients with Advanced Cancer: A Randomised Phase II trial of Dignity Therapy. BMJ Supportive \& Palliative Care, 1(3), 315-321. http://dx.doi.org/10.1136/bmjspcare-2011-000054

Holmerová, I., Jurasková, B., Kalvach, Z., Rohanová, E., Rokosová, M., \& Vanková, H. (2007). Dignity and palliative care in dementia. The Journal of Nutrition, Health \& Aging, 11(6), 489-494.

Houmann, L. J., Rydahl-Hansen, S., Chochinov, H. M., Kristjanson, L. J., \& Groenvold, M. (2010). Testing the feasibility of the Dignity Therapy interview: Adaptation for the Danish culture. BMC Palliat Care, 9, 21. http://dx.doi.org/10.1186/1472-684X-9-21

Kessler, R. C., Birnbaum, H., Bromet, E., Hwang, I., Sampson, N., \& Shahly, V. (2010, February). Age Differences in Major Depression: Results from the National Comorbidity Survey Replication (NCS-R). Psychological Medicine, 40(2), 225-237. http://dx.doi.org/10.1017/S0033291709990213

Kushan, M., \& Vaghee, S. (2015a). Psychiatric Nursing (Mental Health) (Vol. 1). Tehran: Andisherafie.

Kushan, M., \& Vaghee, S. (2015b). Psychiatric Nursing (Mental Health) (Vol. 2). Tehran: Andisherafie.

Miguel, J., Fatima, O., Baltazar, N., Antonio, V. C., \& Antonio, B. (2014). Efficacy of dignity therapy on depression and anxiety in Portuguese terminally Ill patients: A phase II randomized controlled trial. Journal of Palliative Medicine, 17(6), 688-695. http://dx.doi.org/10.1089/jpm.2013.0567

Montross-Thomas, L., Irwin, S., Meier, E., Gallegos, J., Golshan, S., Roeland, E., ... Rodseth, L (2015). Enhancing Legacy in Palliative Care: Study Protocol for a Randomized Controlled Trial of Dignity Therapy Focused on Positive Outcomes. BMC Palliative Care, 14(44), 2-8. http://dx.doi.org/10.1186/s12904-0150041-z

Namdari, K., Molavi, H., Malekpoor, M., \& Kalantari, M. (2011). Effect of Hope Enhancing Training on Behavioral Abilities of Patients with Dysthymia. University of Medical Siences/Shahr Kord, 13(2), 52-60.

Parham, A., Fatehizade, M., \& Mohagheghan, Z. (2013). Snyder Hopes The Three Aspects of The Theory and its Application with Views of The Holy Quran. The Scientific Journal of the Quran and Hadith Sciences University, 10(1), 3-29.

Pashasharifi, H., \& NajafiZand, J. (2013). Positive Psychology. Tehran: Elmi.

Poorghaznein, T., \& Ghaffari, F. (2004). Study of the Relationship between Hope and Self-esteem in Renal Transplant Recipients at Imamreza Hospital in Mashad, Iran. Asrar-Journal of Sabzevar School of Medical Sciences, 11(1), 55-62.

Porafkari, N. (2005). Atkinson \& Hilgard Introduction to Psycholigy (14th ed.). Shahr Ab.

Sadeghirad, B., Haghdoost, A.-A., Amin-Esmaeili, M., Ananloo, E. S., Ghaeli, P., Rahimi-Movaghar, A., ... Barooti, E. (2010). Epidemiology of Major Depressive Disorder in Iran: A Systematic Review and Meta-Analysis. International Journal of Preventive Edicine, 1(2), 81-92.

Sadock, B. J., Sadock, V. A., \& Ruiz, P. (2014). Kaplan and Sadock's Synopsis of Psychiatry: Behavioral Sciences/Clinical Psychiatry (11th ed.). New York: Wolters Kluwer.

Sanatani, M., Schreier, G., \& Stitt, L. (2008). Level and Direction of Hope in Cancer Patients: An Exploratory Longitudinal Study. Supportive Care in Cancer, 16(5), 493-499. http://dx.doi.org/10.1007/s00520-0070336-6

Shafie, M. (2010). The effect of performding cardiac rehabilitaton program on level of hope patient after cronory artery bypass graft. (Master of sciecnces in medical surgical nursing), Mashhad university of Medical sciecnces scholl of nursing and midwifery.

Shafie, M. (2010). The Effect of Performing Cardiac Rehabilitation Program on Level of Hope in Patients after 
Coronary Artery Bypass Graft. (Master of Sciecnces in Medical Surgical Nursing), Mashhad university of Medical sciecnces, Mashhad.

Son, Y. J., Choi, K. S., Park, Y. R., Bae, J. S., \& Lee, J. B. (2009). Depression, Symptoms and The Quality of Life in Patients for End-Stage Renal Disease Am J Nephrol, 29(1), 36-42. http://dx.doi.org/10.1159/000150599

Ustun, T. B., Ayuso-Mateos, J. L., Chatterji, S., Mathers, C., \& Murray, C. J. L. (2004). Global Burden of Depressive Disorders in the Year 2000. The British Journal of Psychiatry, 184(5), 386-392. http://dx.doi.org/10.1192/bjp.184.5.386

Vaghee, S., Javadi, A. R., Mazlom, S. R., Davoudi, N., Gharavi, M. M., \& Zare, M. (2012). The Effect of Dignity Therapy on Hope Level in Patients with Chronic Renal Failure Undergoing Hemodialysis. Life Science Journal, 9(4), 3722-3727.

Vilhauer, J., Cortes, J., Moali, N., Chung, S., Mirocha, J., \& Ishak, W. W. (2013). Improving Quality of Life for Patients with Major Depressive Disorder by Increasing Hope and Positive Expectations with Future Directed Therapy (FDT). Innovations in Clinical Neuroscience, 10(3), 12-22.

\section{Copyrights}

Copyright for this article is retained by the author(s), with first publication rights granted to the journal.

This is an open-access article distributed under the terms and conditions of the Creative Commons Attribution license (http://creativecommons.org/licenses/by/3.0/). 